\title{
Increased Plasma ACTH Responses to Stress in Nonhandled Compared with Handled Rats Require Basal Levels of Corticosterone and Are Associated with Increased Levels of ACTH Secretagogues in the Median Eminence
}

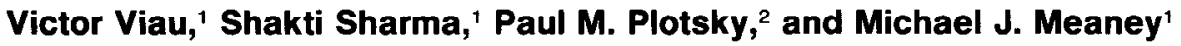 \\ 'Developmental Neuroendocrinology Laboratory, Douglas Hospital Research Center, Departments of Psychiatry, and \\ Neurology and Neurosurgery, Faculty of Medicine, McGill University, Montreal, Canada H4H 1R3 and ${ }^{2}$ The Clayton \\ Foundation Laboratories for Peptide Biology, Peptide Biology Laboratory, The Salk Institute, La Jolla, California 92037
}

Postnatal handling of rat pups is known to alter permanently hypothalamic-pituitary-adrenal (HPA) responses to a wide variety of stressors. As adults, handled $(H)$ and nonhandled (NH) animals also differ in sensitivity to the delayed negativefeedback effects of glucocorticoids on stress-induced HPA activity. However, it is not understood how handling alters neuroendocrine responses to stressful stimuli, and how differences in feedback sensitivity might account for changes in HPA activity both during and following stress. In the present studies, plasma ACTH responses to both restraint and ether stress were significantly greater in NH compared with $H$ animals. Administration of $100 \mu \mathrm{g} / \mathrm{kg}$ corticosterone (B) immediately prior to restraint stress significantly decreased subsequent plasma ACTH responses to restraint to the same extent in $\mathrm{H}$ and $\mathrm{NH}$ animals, suggesting that $\mathrm{H}$ and $\mathrm{NH}$ animals do not differ in glucocorticoid fast feedback. $\mathrm{H}$ and $\mathrm{NH}$ animals adrenalectomized (ADX) 5 d prior to testing did not differ in plasma ACTH responses to restraint stress, demonstrating that the differences between the groups are dependent upon the presence of circulating B. However, the handling effect was apparent in ADX animals provided with a low level of $B$ replacement $(\sim 5-6 \mu \mathrm{g} / \mathrm{dl})$. B replacement significantly decreased plasma ACTH levels under both basal conditions and in response to restraint stress in H/ADX rats. In contrast, although $B$ replacement also decreased basal ACTH levels in ADX/NH rats, there were no differences in plasma ACTH responses to restraint between NH/ADX and $\mathrm{NH} / \mathrm{ADX}+\mathrm{B}$ animals. Thus, plasma ACTH responses to restraint were significantly greater in $A D X+B / N H$ compared with $A D X+B / H$ rats. Thus, a low level of $B$ replacement was able to restore the difference between $\mathrm{H}$ and $\mathrm{NH}$ animals in plasma ACTH responses to stress. This finding shows that the differences between $\mathrm{H}$ and $\mathrm{NH}$ animals in HPA responses to stress can occur independently of stress-induced elevations in plasma $B$ levels. Finally, we found that restingstate levels of corticotropin-releasing hormone (CRH) and

Received May 26, 1992; revised Sept. 8, 1992; accepted Sept. 17, 1992

This research was supported by grants from the Medical Research Council (MRC) to M.J.M. and by NIMH Grant MH45216 to P.M.P. M.J.M. is an MRC scientist.

Correspondence should be addressed to Michael J. Meaney, Developmental Neuroendocrinology Laboratory, Douglas Hospital Research Center, 6875 Boulevard LaSalle, Montreal, Quebec, Canada H4H 1 R3.

Copyright (c) 1993 Society for Neuroscience 0270-6474/93/131097-09\$05.00/0 arginine vasopressin (AVP) in the median eminence were significantly higher in NH animals compared with $\mathrm{H}$ animals. Taken together, these findings suggest that $\mathrm{H}$ and $\mathrm{NH}$ animals differ in delayed negative feedback, and that this difference occurs in response to low levels of $B$ and is reflected in differential rates of CRH and AVP synthesis in hypothalamic neurons. Assuming that the difference in ACTH secretagogues exists in readily releasable storage pools in the median eminence, this would mean that any stress-induced neural signal that activates hypothalamic CRH/AVP neurons would result in a greater release of $\mathrm{CRH}$ and/or AVP in NH animals, leading to a larger ACTH response, and a larger and more prolonged increase in plasma $B$. Thus, differences between $\mathrm{H}$ and NH animals in HPA activity both during and following stress can occur under a variety of stressful conditions and independently of the stress-induced increase in plasma B. These findings are also consistent with earlier findings of increased hippocampal glucocorticoid receptor density in the $\mathrm{H}$ animals.

[Key words: neonatal handling, ACTH, glucocorticoids, glucocorticoid receptors, corticotropin-releasing hormone (CRH), arginine vasopressin (AVP)]

Postnatal handling of rat pups permanently alters hypothalamicpituitary-adrenal (HPA) responses to a variety of stressful stimuli (Levine, 1957, 1962, 1970; Levine et al., 1967; Ader and Grota, 1969; Hess et al., 1969; Meaney et al., 1988a, 1989). These studies have shown that the development of rudimentary endocrine responses to stress is subject to environmental regulation. Moreover, these studies also provide a model for the study of individual differences in neuroendocrine systems, and how such differences might predict vulnerability to stress-induced pathology (see Levine, 1970; Meaney et al., 1988). Nevertheless, despite the long history of the neonatal handling paradigm, we know rather little about the mechanisms that underlie the differences in HPA activity between handled $(\mathrm{H})$ and nonhandled (NH) animals.

In general, adult rats handled daily for the first 3 postnatal weeks exhibit markedly reduced HPA responses to a wide variety of stressors. This difference has been most commonly reported as a smaller increase in plasma corticosterone (B) levels during stress (see references cited above) and a faster return to basal B levels following the termination of the stress (Hess et al., 1969; Meaney et al., 1985a, 1988, 1989). The faster rate of 
decline in plasma $\mathbf{B}$ levels following stress in the $\mathbf{H}$ animals is not due to differences in the plasma clearance rate for $B$, nor is it associated with differences in plasma corticosteroid-binding globulin (CBG) levels (Grota, 1975; Meaney et al., 1989, 1992). Although less well characterized, there is also evidence for a decrease in stress-induced levels of plasma ACTH (Meaney et al., 1989) and bioactive corticotropin-releasing factor in $\mathrm{H}$ animals (Zarrow et al., 1972).

The difference in poststress plasma $B$ levels has been explained on the basis of the enhanced sensitivity to the negativefeedback effects of elevated glucocorticoid levels in the $\mathrm{H}$ animals (Meaney et al., 1991). Indeed, $\mathrm{H}$ animals show a greater sensitivity to the negative-feedback effects of exogenously administered glucocorticoids (Meaney et al., 1989). The differences in negative-feedback sensitivity to elevated glucocorticoid levels and in HPA responses to stress between $\mathrm{H}$ and $\mathrm{NH}$ animals have in turn been associated with the increased density of hippocampal glucocorticoid (type II corticosteroid) receptors in the $\mathrm{H}$ animals (Meaney et al., 1985b, 1987, 1988a, 1989; Sarrieau et al., 1988; Mitchell et al., 1990). Thus, a chronic B treatment regimen that reversed the handling-induced increase in hippocampal glucocorticoid receptor binding capacity, by downregulating receptor levels to values comparable to those of $\mathrm{NH}$ animals, also climinated the difference in poststress B levels (Meaney et al., 1989). The results of these and other studies have suggested that the increase in glucocorticoid receptor sites in the hippocampus is a critical feature for the handling effect on HPA function. The increase in receptor density appears to increase the sensitivity of the hippocampus to elevated levels of circulating glucocorticoids, enhancing the efficacy of negativefeedback inhibition on HPA activity, and serving to reduce poststress secretion of ACTH and B in H animals. This idea is consistent with our emerging view of the hippocampus as a major glucocorticoid target site in HPA regulation (see McEwen et al., 1986; Sapolsky et al., 1986; Dallman et al., 1987; Jacobson and Sapolsky, 1991).

Our current understanding is that the difference between the $\mathrm{H}$ and $\mathrm{NH}$ animals emerges under conditions of elevated glucocorticoid levels, such as those seen during and immediately following stress. Interestingly, young adult $\mathrm{H}$ and $\mathrm{NH}$ animals do not differ in basal levels of either ACTH or B (Meaney et al., 1989, 1992). However, this hypothesis is based largely on measures of plasma $B$, with little information concerning plasma ACTH levels during stress. Dallman's laboratory has shown that in adrenalectomized (ADX) animals provided $\mathrm{B}$ in their drinking water, the termination of ACTH responses following stress was as efficient as in intact animals (Jacobson et al., 1988). Moreover, under certain conditions, the termination of plasma ACTH responses to stress can occur independently of circulating $\mathrm{B}$ (Bradbury et al., 1991). These data clearly challenge the notion that the poststress inhibition of ACTH release is dependent upon the presence of elevated glucocorticoid levels.

In the present study, we have focused on plasma ACTH responses to restraint stress in $\mathrm{H}$ and $\mathrm{NH}$ animals, and provided measures of ACTH secretagogue activity in these animals. In a second study, we compared ACTH responses to stress in $\mathrm{H}$ and NH (1) ADX animals, which lack any glucocorticoid negativefeedback signal; (2) ADX animals provided the equivalent of a basal B signal (ADX $+B$ ), but lacking the negative-feedback signal associated with stress-induced increases in B; and (3) intact, sham-operated animals (SHAM), which possess both basal and stress-induced glucocorticoid signals. These animals were stud- ied $5 \mathrm{~d}$ following ADX. At this time the HPA axis has generally stabilized in ADX + B animals (see Dallman et al., 1987; Bradbury et al., 1991). The results of these studies suggest that differences between $\mathrm{H}$ and $\mathrm{NH}$ animals in poststress HPA activity occur independently of stress-induced changes in circulating $\mathrm{B}$ levels and that the differences in negative-feedback sensitivity between $\mathrm{H}$ and $\mathrm{NH}$ animals are reflected in median eminence levels of corticotropin-releasing hormone $(\mathrm{CRH})$ and arginine vasopressin (AVP) even under basal conditions.

\section{Materials and Methods}

Animals. The animals used in these studies were male Long-Evans, hooded rats (Charles River Canada, St. Constant, Quebec, Canada), the offspring of dams mated in our animal colony. Handling consisted of removing the mother and then the pups from the cage, and placing the pups into a plastic container lined with bedding material for $15 \mathrm{~min}$. The pups, followed by the mother, were then returned to their cage. Handling occurred once per day for the first 3 postnatal weeks. The NH animals were left completely undisturbed throughout this period. On day 22 , the animals were weaned and housed in same-sex, same-treatment groups of three animals per cage. The animals were maintained on a $12 \mathrm{hr}: 12 \mathrm{hr}$ light : dark schedule (lights on at 08:00) with free access to food (Purina Lab Chow) and water. The animals used in these experiments were $4-5$ months of age $(350-400 \mathrm{gm})$ at the time of testing and were randomly selected from approximately 10 litters. All testing was performed during the light phase of the cycle between 12:00 and 15:00.

Adrenalectomy was performed under Metophane (methoxyflurane; Pitman-Moore, Inc., Washington Crossing, NJ) anesthesia, and all ADX animals were provided with $0.9 \%$ saline as drinking water. For studies of median eminence content of CRH and AVP, animals were rapidly (i.e., $<10 \mathrm{sec}$ ) killed by decapitation following removal from the home cage between 11:00 and 13:00. All procedures were conducted in accordance with the guidelines of the Canadian Council on Animal Care and the McGill University Animal Carc Committce.

Stress testing and blood sampling. Three days prior to testing, animals were implanted with indwelling jugular catheters under Metophane anesthesia and single housed for the remainder of the study. Restraint stress was performed using tubular, plastic restrainers lined with foam rubber. The animals were placed into the restrainers for a $20 \mathrm{~min}$ period. A blood sample $(\sim 150 \mu$ l) was taken immediately before the animal was placed into the restrainer and less than $10 \mathrm{sec}$ following removal from the home cage. This sample was used to obtain estimates of basal ACTH and B levels prior to stress. Blood samples $(\sim 150 \mu \mathrm{l})$ were then taken from the same animals via a jugular catheter at various times during restraint. In one experiment animals were injected subcutaneously with $100 \mu \mathrm{g} / \mathrm{kg} \mathrm{B}$ (in EtOH:saline, 1:9) 3 min prior to restraint testing in order to examine fast-feedback effects. In this experiment, blood samples were taken immediately following a $10 \mathrm{~min}$ period of restraint. Ether stress was performed by placing animals into a large, covered beaker containing ether-soaked cotton balls. The animals were removed from the beaker after $2.5 \mathrm{~min}$ and a blood sample was taken immediately, and at various times afterward. Blood samples for corticosterone or CBG measurement were taken into heparinized tubes, placed on ice, centrifuged, and stored at $-30^{\circ} \mathrm{C}$ until assayed. Blood samples for ACTH assays were taken in tubes containing EDTA and Trasylol, centrifuged, and stored at $-80^{\circ} \mathrm{C}$.

In a separate study, animals were ADX $5 \mathrm{~d}$ prior to testing. Immediately following adrenalectomy, one-half of the animals were implanted with fused $150 \mathrm{mg}$ steroid pellets comprised of $50 \% \mathrm{~B}$ and $50 \%$ cholesterol (see Meyer et al., 1979). SHAM animals received the anesthetic and bilateral incisions above the adrenals. Two days later all animals were implanted with jugular catheters. Stress testing was performed on day $5,3 \mathrm{~d}$ following catheter implants.

Radioimmunoassays. Plasma B was measured by the radioimmunoassay of Krey et al. (1975) with a highly specific B antiserum (B3163, Endocrine Sciences, Tarzana, CA), ${ }^{3} \mathrm{H}-\mathrm{B}(101 \mathrm{Ci} / \mathrm{mmol}$; New England Nuclear, Boston, MA) as tracer, and $1 \mu 1$ of plasma. The minimum level of detection with the assay was $10 \mathrm{pg}$. The antiserum cross-reacts slightly with desoxycorticosterone $(\sim 4 \%)$, but not with cortisol $(<1 \%)$. The intra- and interassay coefficients of variation were $8.9 \%$ and $11.2 \%$, respectively.

Plasma $(25 \mu \mathrm{l})$ ACTH was measured by the radioimmunoassay de- 
scribed by Walker et al. (1990) with an ACTH antiserum (IgG Corp., Nashville, TN) and ${ }^{125}$ I-ACTH (Incstar, Stillwater, MN) as tracer. The ACTH antibody cross-reacts $100 \%$ with $\mathrm{ACTH}_{1-39}, \mathrm{ACTH}_{1-18}$, and ACTH $_{1-24}$ but less than $1 \%$ with $\mathrm{ACTH}_{1-10}, \beta$-endorphin, $\alpha$ - and $\beta$-melanocyte-stimulating hormone ( $\beta$-MSH), and $\alpha$ - and $\beta$-lipotropin. The intra- and interassay coefficients of variation were $18 \%$ and $8 \%$, respectively. The minimal detectable level was $1 \mathrm{pg}$.

For peptide extraction, median eminence fragments were placed in 2 $\mathrm{ml}$ of $45^{\circ} \mathrm{C} 1.0 \mathrm{~N}$ acetic acid: $0.5 \mathrm{~N} \mathrm{HCl}(1: 1 \mathrm{v} / \mathrm{v})$ containing pepstatin $(4.5 \mu \mathrm{g} / \mathrm{ml})$ and, for CRH extraction, $0.5 \% \beta$-mercaptoethanol. After 5 min, solutions were cooled, sonicated, and centrifuged $(5000 \times g, 30$ $\min , 4^{\circ} \mathrm{C}$ ). Supernatants were then lyophilized and frozen at $-70^{\circ} \mathrm{C}$. Immediately prior to assay, samples were reconstituted in $0.5 \mathrm{ml}$ assay buffer neutralized.

CRH levels were determined by radioimmunnassay (see Plotsky et al., 1985) using antiserum rC-70 (Dr. W. Vale, The Salk Institute, La Jolla, CA) at a final dilution of 1:150,000 with synthetic rat CRH-41 as standard (Dr. J. Rivier, The Salk Institute, La Jolla, CA) and iodinated by the chloramine-T method for tracer. The minimal detectable level was $2 \mathrm{pg} / \mathrm{ml}$. The intra- and interassay coefficients of variation were $3.6 \%$ and $10.6 \%$, respectively.

AVP and oxytocin radioimmunoassays (see Plotsky et al., 1985) were performed using antisera R-71 to AVP and R-421 to oxytocin (Dr. D. A. Fisher, Harbor-UCLA Medical Center, Torrance, CA) in final dilutions of $1: 112,000$ and 1:12,800, respectively. Synthetic peptides (Dr. J. Rivier) were used for tracer preparation (see above) and standards. The minimal detectable level for each peptide was $1 \mathrm{pg} / \mathrm{ml}$. The intraand interassay coefficients of variation were $6.2 \%$ and $12.1 \%$. The crossreactivity of synthetic oxytocin with the AVP antiserum was $<0.2 \%$, while that of synthetic AVP for the oxytocin antiserum was $<0.02 \%$. The results of the CRH, AVP, and oxytocin radioimmunoassays are expressed as $\mu \mathrm{g} / \mathrm{mg}$ protein.

Plasma CBG assay. Plasma CBG levels were measured by a method described by Martin et al. (1975) in plasma samples taken $2 \mathrm{hr}$ into the light cycle (10:00). For the measurement of CBG, endogenous steroids were removed from plasma samples by passing the sample through a $10 \times 1 \mathrm{~cm}$ Sephadex LH-20 column and the plasma was diluted 1:50 with TEDGM ( $30 \mathrm{~mm}$ Tris, $1 \mathrm{~mm}$ EDTA, $10 \mathrm{~mm}$ sodium molybdate, $10 \% \mathrm{v} / \mathrm{v}$ glycerol, and $1 \mathrm{~mm}$ dithiothreitol; $\mathrm{pH} 7.4)$. Aliquots $(225 \mu \mathrm{l})$ of the diluted plasma were then incubated in buffer $(150 \mu \mathrm{l})$ containing a saturating $80 \mathrm{~nm}$ concentration of ${ }^{3} \mathrm{H}-\mathrm{B}$ for $90 \mathrm{~min}$ at $2-4^{\circ} \mathrm{C}$ (see Martin et al., 1975). Nonspecific binding was defined in parallel incubations by a 200 -fold excess of cold $B$. Separation of bound from free was achieved using Sephadex LH-20 columns $(4 \times 1 \mathrm{~cm})$, equilibrated with TEDGM, made from disposable pipette tips. Following the incubation, $100 \mu \mathrm{l}$ of the incubates were washed into the columns with $100 \mu \mathrm{l}$ of TEDGM. The columns were eluted $30 \mathrm{~min}$ later with $500 \mu \mathrm{l}$ of TEDGM into minivials, which were then filled with $5 \mathrm{ml}$ of Liquiscent (National Diagnostics, Somerville, NJ) and counted in a Packard scintillation counter at $40 \%$ efficiency. Protein content was determined by the method of Bradford (1976), and the results were expressed as picomoles of binding $/ \mathrm{mg}$ protein.

Glucocorticoid receptor occupancy. Glucocorticoid receptor occupancy in hippocampal tissue from $\mathrm{H}$ and $\mathrm{NH}$ animals was estimated by comparing receptor binding in ADX + B animals, prepared as described above, with animals adrenalectomized (ADX) $16 \mathrm{hr}$ prior to death using a previously described procedure (see Reul and De Kloet, 1985; Meaney et al., 1988b: Sapolsky et al., 1990). Following decapitation, the brain was quickly removed and placed on ice, and the hippocampus was dissected, frozen on dry ice, and stored at $-80^{\circ} \mathrm{C}$. Tissue was homogenized in TEDGM ( $\mathrm{pH}$ adjusted to 7.4) and the homogenate was centrifuged at $2^{\circ} \mathrm{C}$ for $60 \mathrm{~min}$ at $105,000 \times g$ in a Beckman $\mathrm{L} 8-80$ ultracentrifuge. Aliquots $(150 \mu \mathrm{l})$ of the soluble fraction prepared from the hippocampal tissue were incubated with $100 \mu \mathrm{l}$ buffer containing a saturating $20 \mathrm{~nm}$ concentration of ${ }^{3} \mathrm{H}$-dexamethasone $(87.0 \mathrm{Ci} / \mathrm{mmol}$; New England Nuclear, Boston, MA) at $0-2^{\circ} \mathrm{C}$ for $4 \mathrm{hr}$. Nonspecific binding was determined in parallel incubations containing a 200 -fold excess of unlabeled synthetic glucocorticoid, RU 28362. RU 28362 has been shown to bind to the glucocorticoid receptor selectively, showing very little affinity for the mineralocorticoid receptor (see Reul and De Kloet, 1985; McEwen et al., 1986). Sephadex LH-20 columns $(4 \times 1 \mathrm{~cm})$, equilibrated with TEDGM, made from disposable pipette tips, were used to separate bound from unbound steroid. Following the incubation, $100 \mu \mathrm{l}$ of the incubates were washed into the columns with $100 \mu \mathrm{l}$ of TEDGM. The columns were eluted $30 \mathrm{~min}$ later with $500 \mu \mathrm{l}$ of TEDGM

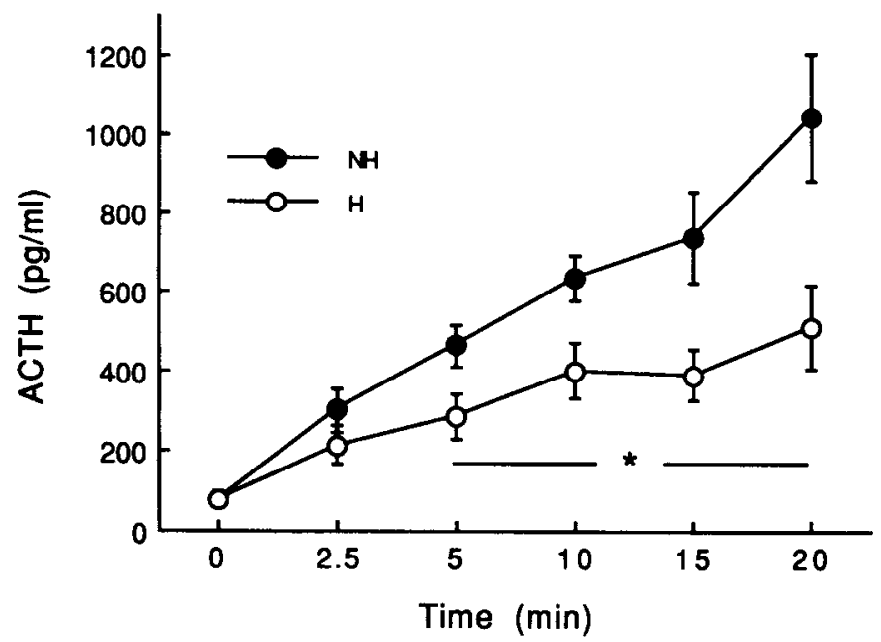

Figure 1. Plasma ACTH levels in $\mathrm{H}$ and $\mathrm{NH}$ rats ( $n=8$ per group) sampled prior to and at various time points during restraint stress. Values above the line with the asterisks $\left(^{*}\right)$ differ at $p<0.05$.

into minivials, which were then filled with $5 \mathrm{ml}$ of Liquiscent (National Diagnostics, Somerville, NJ) and counted in a Packard scintillation counter at $40 \%$ efficiency. Protein content was determined by the method of Bradford (1976) and the results were expressed as femtomoles of binding/mg protein. Protein concentrations ranged from 300-500 $\mu \mathrm{g} /$ $\mathrm{ml}$.

In the $\mathrm{ADX}+\mathrm{B}$ animals, a $4 \mathrm{hr}$ incubation period reflects binding only to the unoccupied receptor sites; hormone-bound receptor sites, whether soluble or DNA bound, are masked by the endogenous ligand. In ADX animals the absence of steroid renders receptor sites available for radioligand binding in the soluble fraction and decapitation occurs at a time that precedes the upregulation of receptor sites (see McEwen et al., 1986). Thus, receptor binding in $16 \mathrm{hr}$ ADX animals serves as an estimate of the total receptor binding capacity. It is then possible to estimate the receptor occupancy by subtraction (ADX values - binding at $4 \mathrm{hr}$ ). These data were expressed as the percentage of receptor occupancy [(ADX binding - ADX $+B$ binding)/ $\triangle D X$ binding] for both $\mathrm{H}$ and $\mathrm{NH}$ animals.

Statistical analysis. Integrated plasma ACTH levels (area under the curve) were calculated using the trapezoidal method. Data derived from group $\times$ time designs were analyzed using analysis of variance with one repeated measure (time of sample), and Scheffé post hoc tests were used, where appropriate, to explore the source of significant effects. Group data were analyzed using unpaired $t$ tests.

\section{Results}

\section{Plasma ACTH during stress}

Integrated plasma ACTH levels were significantly $(p<0.01)$ higher during the $20 \mathrm{~min}$ restraint stress in the $\mathrm{NH}$ animals $(409.8 \pm 60$ vs. $243.8 \pm 40 \mathrm{pg} / \mathrm{ml} / \mathrm{min})$. Differences in plasma ACTH levels were apparent at 5, 10, 15, and 20 min following the onset of restraint (Fig. 1). Plasma ACTH levels in NH animals were significantly $(p<0.05)$ higher at 20 min into restraint than at any other time point. In contrast, plasma ACTH levels in the $\mathrm{H}$ animals peaked by $10 \mathrm{~min}$ (i.e., there was no statistically reliable difference between the 10 and 20 min samples in the $H$ animals). The difference in plasma ACTH levels was reflected in significantly higher plasma levels of B in the NH animals. Thus, integrated B levels over the same time period were significantly $(p<0.01)$ higher in the $\mathrm{NH}$ animals $(25.6 \pm 1.3 \mathrm{vs}$. $16.4 \pm 1.3 \mu \mathrm{g} / \mathrm{dl} / \mathrm{min}$ ).

The results for ether stress were comparable to those for restraint (data not shown). Integrated plasma ACTH levels over the $20 \mathrm{~min}$ period following exposure to ether were significantly 


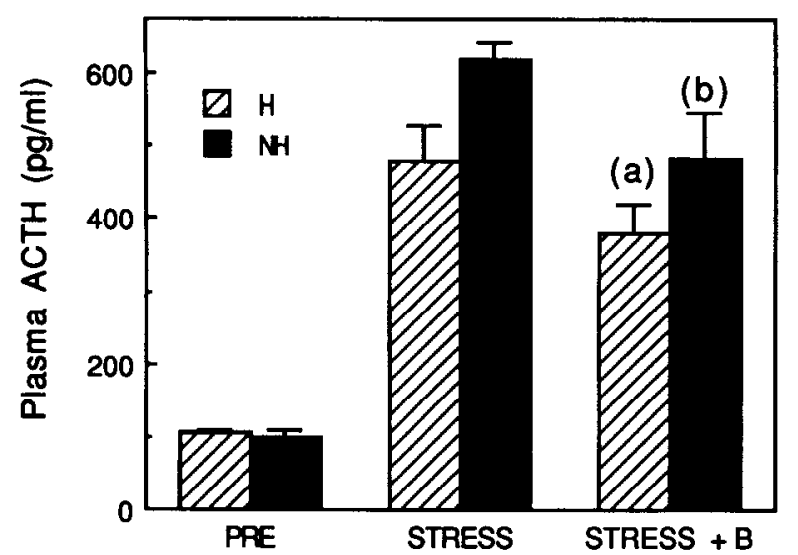

Figure 2. Plasma ACTH levels during restraint stress in $\mathrm{H}$ or $\mathrm{NH}$ animals treated with $100 \mu \mathrm{g} / \mathrm{kg} \mathrm{B}$ or saline/EtOH vehicle. Samples were taken $10 \mathrm{~min}$ following the onset of restraint. The prestress samples $(P R E)$ were taken from untreated animals. $a$, differs at $p<0.05$ from vehicle-treated $(S T R E S S) \mathrm{H}$ animals; $b$, differs at $p<0.05$ from vehicletreated (STRESS) H animals; $n-5$ or 6/group.

$(p<0.01)$ higher in the NH animals $(1453.6 \pm 177$ vs. 902.0 $\pm 148 \mathrm{pg} / \mathrm{ml} / \mathrm{min}$ ).

\section{Glucocorticoid fast feedback}

Administration of exogenous $100 \mu \mathrm{g} / \mathrm{kg}$ B $3 \mathrm{~min}$ prior to restraint stress significantly $(p<0.05)$ reduced plasma ACTH levels in both $\mathrm{H}$ and $\mathrm{NH}$ animals (Fig. 2). As expected, $\mathrm{NH}$ animals showed significantly $(p<0.05)$ higher plasma ACTH levels and therefore the suppression data were analyzed as the percentage change following $\mathrm{B}$ treatment. There was no difference in the magnitude of the suppression of ACTH in $\mathrm{H}(29 \pm$ $2 \%)$ vs. $\mathrm{NH}(28 \pm 3 \%)$ following pretreatment with $\mathrm{B}$. The magnitude of the suppression of restraint-induced increases in plasma $\Lambda \mathrm{CTH}$ was not great, and this is consistent with the recent finding using a very similar paradigm (Young et al., 1990).

\section{Adrenalectomy with $B$ replacement}

The $50 \% \mathrm{~B}$ pellets provided a plasma $\mathrm{B}$ signal that was in the low physiological range $(\mathrm{ADX}+\mathrm{B} / \mathrm{H}, 5.6 \pm 0.9 \mu \mathrm{g} / \mathrm{dl} ; \mathrm{ADX}+\mathrm{B} /$ $\mathrm{NH}, 6.2 \pm 1.2 \mu \mathrm{g} / \mathrm{dl}$ ) and comparable to the integrated B levels achieved over the diurnal cycle (see Dallman et al., 1987). These animals did not differ in plasma CBG levels (Table 1). The same plasma samples were then used to calculate the percentage of free B using the procedure described by Martin et al. (1975). Based on these estimates, the concentration of free $B$ was 10.4 $\pm 3.2 \mathrm{~nm}$ in $\mathrm{ADX}+\mathrm{B} / \mathrm{N}$ rats and $11.7 \pm 2.2 \mathrm{~nm}$ in $\mathrm{ADX}+\mathrm{B} /$ $\mathrm{NH}$ rats. These $\mathrm{B}$ levels resulted in comparable levels of glucocorticoid receptor occupancy in hippocampal tissue (ADX $+B$ / $\mathrm{H}, 37.3 \pm 10 \% ; \mathrm{ADX}+\mathrm{B} / \mathrm{NH}, 41.2 \pm 8 \% ; n=6$ per group) This level of receptor occupancy corresponds closely to the study of Sapolsky et al. (1990), where glucocorticoid receptor occupany was examined over a wide range of plasma B levels. Note that these data are presented as the percentage occupancy of the total receptor population for each group. As reported in several previous studies, receptor binding in animals ADX $16 \mathrm{hr}$ prior to death differed significantly $(H, 151 \pm 9 \mathrm{fmol} / \mathrm{mg}$ protein; $\mathrm{NH}$, $103 \pm 10 \mathrm{fmol} / \mathrm{mg}$ protein; $p<0.01 ; n=6$ per group), reflecting the increased hippocampal glucocorticoid receptor density in the $\mathrm{H}$ animals.

Plasma ACTH levels were significantly $(p<0.0001)$ elevated
Table 1. Mean \pm SEM plasma CBG levels (pmol/mg protein) in $\mathbf{H}$ and $\mathrm{NH}$ animals $5 \mathrm{~d}$ following $\mathrm{ADX}, \mathrm{ADX}+\mathrm{B}$, or SHAM treatment $(n=8$ per group)

\begin{tabular}{llll} 
& SHAM & ADX & ADX + B \\
\hline H & $11.4 \pm 0.5$ & $20.5 \pm 1.9^{*}$ & $14.1 \pm 0.7$ \\
NH & $13.2 \pm 0.8$ & $25.2 \pm 1.6^{*}$ & $14.8 \pm 1.1$ \\
\hline
\end{tabular}

* Significantly different from SHAM animals $(p<0.01)$.

following $\mathrm{ADX}$ in both $\mathrm{H}$ and $\mathrm{NH}$ rats $(\mathrm{ADX} / \mathrm{H}, 655 \pm 63 \mathrm{pg} /$ $\mathrm{ml}$; SHAM/H, $65 \pm 6 \mathrm{pg} / \mathrm{ml}$; ADX/NH, $727 \pm 85 \mathrm{pg} / \mathrm{ml}$; SHAM/ $\mathrm{NH}, 60 \pm 7 \mathrm{pg} / \mathrm{ml}$ ). B replacement was sufficient to reverse at least partially the ADX-induced increase in basal plasma ACTH in both $\mathrm{H}(\mathrm{ADX}+\mathrm{B} / \mathrm{H}, 139 \pm 46 \mathrm{pg} / \mathrm{ml})$ and $\mathrm{NH}$ animals $(\mathrm{ADX}+\mathrm{B} / \mathrm{NH}, 145 \pm 76 \mathrm{pg} / \mathrm{ml}$; also see Fig. 3). Moreover, the $\mathrm{ADX}$-induced increase in plasma $\mathrm{CBG}$ levels was reversed with $B$ replacement in both $\mathrm{H}$ and NH animals (see Table 1).

As in previous experiments, plasma ACTH levels in response to restraint stress were significantly $(p<0.05)$ higher in the intact (SHAM) NH animals compared with intact (SHAM) $\mathrm{H}$ animals both during and following stress (Fig. 3, Table 2). The integrated plasma $\mathrm{B}$ response to restraint was also significantly higher in the SHAM/NH compared with SHAM/H rats $(30.3$ \pm 4.1 vs. $20.9 \pm 2.2 \mu \mathrm{g} / \mathrm{dl} / \mathrm{min} ; t=1.91, p<0.05)$. H/ADX and NH/ADX animals showed a significant $(p<0.0001)$ increase in plasma ACTH levels in response to restraint stress. At 40 min following the termination of stress, plasma ACTH levels were subsequently reduced to values that were comparable to those observed prior to stress. There were no significant differences in plasma ACTH levels at any time between $\mathrm{ADX} / \mathrm{H}$ and ADX/NH animals. Among the NH animals, plasma ACTH levels did not differ between $\mathrm{ADX}$ and $\mathrm{ADX}+\mathrm{B}$ animals at any time point, except the basal sample (see Fig. 3, PRE). Moreover, the integrated plasma ACTH responsc was virtually indentical in these animals (see Table 2). In contrast, among $\mathrm{H}$ animals plasma ACTH levels were significantly $(p<0.05)$ lower in the $\mathrm{ADX}+\mathrm{B}$ animals than in the ADX animals at 20 and $40 \mathrm{~min}$ poststress (see Fig. 3). Plasma ACTH levels in $\mathrm{ADX}+\mathrm{B} / \mathrm{H}$ animals were lower than in $\mathrm{ADX} / \mathrm{H}$ during stress, but these differences during restraint were partially masked by the variability among the ADX $+B$ animals. Nevertheless, these differences approached significance at $10 \mathrm{~min}(p=0.05)$ and $20 \mathrm{~min}$ of restraint stress $(p>0.05<0.10)$, and were significant at 20 $\min (p<0.05)$ and $40 \min (p<0.01)$ following stress. Note as well that the integrated plasma $A C T H$ level in the $A D X+B / H$ animals was significantly $(p<0.01)$ lower than that for the ADX/H animals (see Table 2 ). In contrast, the integrated plasma $\mathrm{ACTH}$ response to restraint in $\mathrm{ADX}+\mathrm{B} / \mathrm{NH}$ animals did not differ from that of ADX/NH animals. Most importantly, there were highly significant differences in $A C T H$ responscs to restraint stress between $\mathrm{ADX}+\mathrm{B} / \mathrm{H}$ and $\mathrm{ADX}+\mathrm{B} / \mathrm{NH}$ animals (see Fig. 3). ADX $+\mathrm{B} / \mathrm{NH}$ animals had significantly higher plasma ACTH levels at 10 min into restraint, and at both 20 and $40 \mathrm{~min}$ following restraint. Overall, the integrated plasma ACTH response to restraint was almost twofold higher $(p<0.01)$ in the $\mathrm{ADX}+\mathrm{B} / \mathrm{NH}$ compared with $\mathrm{ADX}+\mathrm{B} / \mathrm{H}$ animals (see Table 2). Finally, a striking difference between these groups was the magnitude of the increase in plasma ACTH during stress. We estimated the peak ACTH to stress by averaging the two samples taken during stress (10 and $20 \mathrm{~min}$ ) and subtracting the 

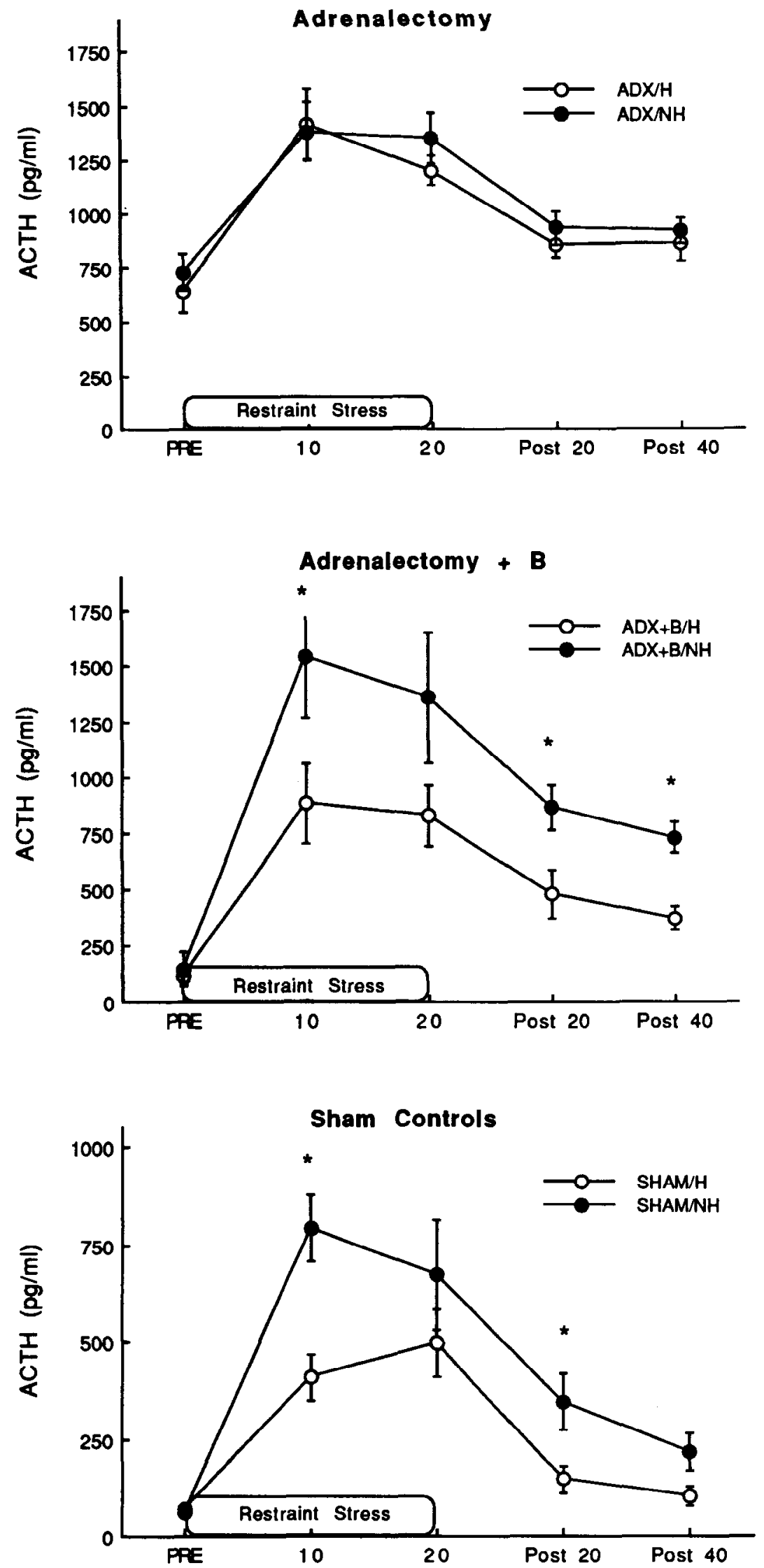

Figure 3. Plasma ACTH levels prior to (PRE), during, and at 20 and $40 \mathrm{~min}$ following a 20 min restraint stress in $\mathrm{ADX}, \mathrm{ADX}+\mathrm{B}$, and SHAM $\mathrm{H}$ and $\mathrm{NH}$ animals. The asterisks indicate values that differ at $p<0.05$. 
Table 2. Mean \pm SEM integrated plasma ACTH levels (pg/ml $/ \mathrm{min})$ with restraint stress in $H$ and NH animals $5 \mathrm{~d}$ following $A D X$, $A D X+B$, or SHAM treatment ( $n=8$ per group)

\begin{tabular}{lllc} 
& SHAM & ADX & ADX +B \\
\hline H & $326.7 \pm 68^{*}$ & $1031.5 \pm 61$ & $608.9 \pm 142^{* *}$ \\
NH & $448.2 \pm 83$ & $1070.1 \pm 111$ & $1091.1 \pm 111$
\end{tabular}

* Significantly different from same-treatment $\mathrm{NH}$ animals $(p<0.05)$.

** Significantly different from same-treatment NH animals $(p<0.01)$.

basal (Fig. 3, PRE) ACTH value for each animal. This analysis revealed that the $A C T H$ response to restraint was significantly higher in $\mathrm{ADX}+\mathrm{B} / \mathrm{NH}$ rats compared with all other groups, including $A D X$ animals (Table 3 ). These data further underscore the differences between $\mathrm{ADX}+\mathrm{B} / \mathrm{H}$ and $\mathrm{ADX}+\mathrm{B} / \mathrm{NH}$ animals.

\section{ACTH secretagogues}

$\mathrm{CRH}$ and AVP content in median eminence extracts from intact $\mathrm{H}$ and $\mathrm{NH}$ animals differed significantly $(p<0.01$; Fig. 4). Under resting-state conditions, CRH content was $85 \%$ higher and AVP content $45 \%$ higher in the $\mathrm{NH}$ animals. There were no differences in oxytocin levels $(\mathrm{H}, 301.6 \pm 53 \mu \mathrm{g} / \mathrm{mg}$ protein; $\mathrm{NH}, 313.9 \pm 58 \mu \mathrm{g} / \mathrm{mg}$ protein).

\section{Discussion}

NH animals showed higher plasma ACTH levels during both restraint and ether stress than $\mathrm{H}$ animals. However, these differences in ACTH secretion between $\mathrm{H}$ and $\mathrm{NH}$ animals were apparently not due to differences in glucocorticoid fast feedback. Glucocorticoid administration immediately prior to restraint stress moderately dampened plasma ACTH responses, and the magnitude of the supression was similar in $\mathrm{H}$ and $\mathrm{NH}$ animals (see Fig. 2).

Among the earlier handling studies, perhaps the most reliable and pronounced difference in the HPA response to stress between $\mathrm{H}$ and $\mathrm{NH}$ animals was the elevated poststress levels of $\mathrm{B}$ in the $\mathrm{NH}$ animals. Even when the groups are statistically equated for differences in $B$ achieved during stress, the rate of decline in plasma $\mathrm{B}$ is faster in the $\mathrm{H}$ animals (Meaney et al., 1989). In previous reports, we speculated that these differences occurred in response to the poststress negative-feedback signal associated with elevated glucocorticoid levels. $\mathrm{H}$ and $\mathrm{NH}$ animals differ in delayed negative-feedback sensitivity to elevated glucocorticoid levels (Meaney et al., 1989). Exogenous administration of either dexamethasone or B $3 \mathrm{hr}$ prior to testing produces a greater suppression of stress-induced HPA activity in $\mathrm{H}$ animals than in $\mathrm{NH}$ animals; the $\mathrm{ID}_{50}$ values for both steroids are about 5-10 times lower in the $\mathrm{H}$ animals. Thus, we

Table 3. Mean \pm SEM stress-induced elevation in plasma ACTH in $\mathrm{H}$ and $\mathrm{NH}$ animals $5 \mathrm{~d}$ following $\mathrm{ADX}, \mathrm{ADX}+\mathrm{B}$, or SHAM treatment

\begin{tabular}{lllc} 
& SHAM & ADX & ADX+B \\
\hline H & $385.0 \pm 63^{*}$ & $715.2 \pm 81$ & $740.8 \pm 126$ \\
NH & $672.8 \pm 91 \dagger$ & $639.1 \pm 101$ & $1457.7 \pm 240 \dagger,{ }^{* *}$
\end{tabular}

Values are (St10 + St20)/2 - prestress levels), and are the same as in Figure 3.

* Significantly different from remaining $\mathrm{H}$ animals $(p<0.01)$.

$\uparrow$ Significantly different from same-treatment $\mathrm{H}$ animals $(p<0.01)$

** Significantly different from remaining NH animals $(p<0.01)$.
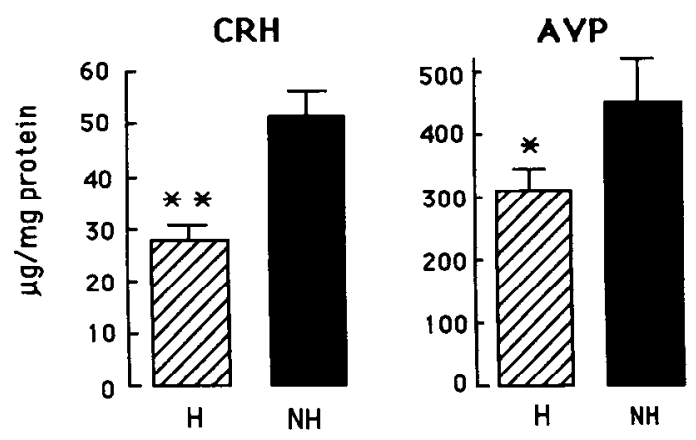

Figure 4. Median eminence levels of $\mathrm{CRH}$ and AVP in $\mathrm{H}$ and $\mathrm{NH}$ animals $\left(n=8\right.$ per group). ${ }^{*},{ }^{* *}$, values that differ at $p<0.05, p<$ 0.01 , respectively.

believed that the difference in poststress HPA activity between $\mathrm{H}$ and $\mathrm{NH}$ animals was associated with a differential response to the negative-feedback signal associated with elevated glucocorticoid levels achieved during stress. However, the differences in ACTH secretion revealed in this study, together with the previous findings from Dallman's group, clearly raise an alternative hypothesis.

The integrated ACTH response to both restraint and ether was substantially higher in the $\mathrm{NH}$ animals than in the $\mathrm{H}$ animals. Maximal levels of B are achieved in response to levels of ACTH that are lower than normally occur in response to stress. However, the adrenal is known to respond not only to the magnitude of the elevation in ACTH, but also to the integrated ACTH signal (i.e., ACTH levels over time). A higher integrated level of ACTH results in a prolonged period of elevated B secretion. Thus, the differences in poststress $\mathrm{B}$ levels in $\mathrm{H}$ and $\mathrm{NH}$ animals might be associated with the differences in the integrated ACTH levels and not with a poststress, negative-feedback signal.

In order to test this idea, we examined plasma $\mathrm{ACTH}$ responses to stress in ADX, ADX + B, SHAM, $\mathrm{H}$, and $\mathrm{NH}$ animals. First, it is important to note that there were no differences in plasma ACTH levels at any time between ADX/H and ADX/ $\mathrm{NH}$ animals at $5 \mathrm{~d}$ following ADX. Thus, the removal of circulating B completely eliminated the differences in ACTH responses to stress between $\mathrm{H}$ and $\mathrm{NH}$ animals. There remains the possibility that differences between ADX/NH and ADX/H animals may have emerged had the animals been examined at a longer time following ADX. Nevertheless, the comparable ACTH responses in these animals is consistent with the idea that differences in HPA activity between $\mathrm{H}$ and $\mathrm{NH}$ animals occur in response to differences in glucocorticoid negative-feedback sensitivity. The question, then, is whether this difference in negative-feedback inhibition occurs in response to basal or stress-induced levels of $\mathrm{B}$. The critical comparison here involves the $A D X+B$ groups, where the basal B signal has been maintained, but where the negative-feedback signal associated with stress-induced increases in $\mathrm{B}$ has been eliminated. If the differences in poststress HPA activity between $\mathrm{H}$ and $\mathrm{NH}$ animals are dependent upon negative-feedback inhibition associated with elevated glucocorticoid levels then $\mathrm{ADX}+\mathrm{B} / \mathrm{H}$ and $\mathrm{ADX}+\mathrm{B} /$ $\mathrm{NH}$ animals should not differ in plasma ACTH levels. This was clearly not the case. $\mathrm{H}$ and $\mathrm{NH}$ animals provided with only basal levels of B replacement, like intact animals, showed significant differences in plasma ACTH levels both during and following stress (see Fig. 3, Table 2). Thus, the difference in 
poststress HPA activity between $\mathrm{H}$ and $\mathrm{NH}$ animals is not uniquely dependent upon a stress-induced elevation in plasma $B$ levels. These results are consistent with recent studies showing that plasma ACTH levels during and following stress are tightly regulated by basal glucocorticoid levels (see Akana et al., 1992).

It is also important to note the specificity of this effect. The $B$ replacement regimen used in this study was sufficient to attenuate greatly the ADX-induced increase in basal ACTH and plasma $\mathrm{CBG}$ in both $\mathrm{H}$ and $\mathrm{NH}$ animals, but altered stressinduced $\mathrm{ACTH}$ secretion only in the $\mathrm{H}$ animals. A number of previous studies have shown that in laboratory rats, B pellet replacement of this order of magnitude is sufficient to correct basal ACTH secretion (Akana et al., 1988; Jacobson et al., 1988) and CBG production (Levin et al., 1987), but not stress-induced increases in plasma $\mathrm{ACTH}$; these findings are comparable to our data with $\mathrm{ADX}+\mathrm{B} / \mathrm{NH}$ rats. Indeed, the largest plasma ACTH response to restraint stress was observed in the ADX $+B$ / NH animals (see Table 3 ). By contrast, basal B replacement did at least partially attenuate the ACTH hypersecretion with stress in $\mathrm{ADX}+\mathrm{B} / \mathrm{H}$ rats. The reduced $\mathrm{ACTH}$ secretion in response to stress in the $\mathrm{ADX}+\mathrm{B} / \mathrm{H}$ animals is consistent with previous data showing increased glucocorticoid negative-feedback sensitivity in $\mathrm{H}$ animals. Taken together, these data indicate that differences in HPA response to stress between $\mathrm{H}$ and $\mathrm{NH}$ animals are dependent upon the presence of glucocorticoids, but arc not dependent upon stress-induced elevations in glucocorticoid levels.

These findings also suggest that negative-feedback differences between $\mathrm{H}$ and $\mathrm{NH}$ animals can occur in response to basal $\mathrm{B}$ levels. These differences appear to be reflected in median eminence levels of CRH and AVP (but not oxytocin). Thus, under resting-state conditions, $\mathrm{CRH}$ and AVP levels in the median eminence were significantly higher in the $\mathrm{NH}$ animals. We have recently found that hypothalamic CRH mRNA levels are about 2.5-fold higher in $\mathrm{NH}$ compared with $\mathrm{H}$ animals (P. M. Plotsky and M. J. Meaney, unpublished observations). Thus, under resting conditions, hypothalamic CRH and AVP synthesis appears to be elevated in NH rats, a difference that occurs in the presence of basal glucocorticoid levels.

The differences in median eminence levels of $\mathrm{CRH}$ and AVP offer an important insight into understanding the nature of the differences in glucocorticoid negative-feedback between $\mathrm{H}$ and $\mathrm{NH}$ animals. First, it should noted that $\mathrm{H}$ and $\mathrm{NH}$ animals do not differ in basal levels of ACTH or B (Meaney et al., 1989, 1992; see also Figs. 1-3). It seems likely, therefore, that the differences in CRH and AVP represent differences in readily releasable storage pools of these peptides in axon terminals located in the median eminence. The excitatory signal at the level of the paraventricular nucleus of the hypothalamus associated with stress likely results in greater $\mathrm{CRH}$ and AVP release in the $\mathrm{NH}$ animals. This, in turn, would result in a greater plasma ACTH signal. This idea is consistent with the finding that $\mathrm{H}$ and $\mathrm{NH}$ animals differ in plasma ACTH responses to a wide variety of stressors. Indeed, the differences in the terminal pools of CRH and AVP suggest that $\mathrm{H}$ and $\mathrm{NH}$ animals would differ in stressors mediated by either secretagogue. Note that pituitary ACTH responses to both restraint and ether stress appear to be mediated by dynamic variations in both CRH and AVP (Linton et al., 1985; Nakane et al., 1985; Antoni, 1986; Rivier and Plotsky, 1986; Plotsky, 1987). This hypothesis has been at least partially confirmed in one recent study. Plotsky and Meaney (unpublished observations) found that $\mathrm{CRH}$ release from the median eminence in response to restraint stress was significantly greater in $\mathrm{NH}$ compared with $\mathrm{H}$ rats.

It is also important to note that $\mathrm{ADX}+\mathrm{B}$ animals do not differ in corticotrope sensitivity to CRH (Akana et al., 1986), and that differences in ACTH release in response to stress most likely reflect differences in neural regulatory components of ACTH secretion (Plotsky et al., 1986; also see Akana et al., 1988). This idea is also consistent with available information on the role of the hippocampus in mediating glucocorticoid inhibition of HPA activity. Hippocampal lesions result in a prolonged elevation of B following stress (Sapolsky et al., 1984). Herman et al. (1989) found that hippocampal lesions resulted in increased $\mathrm{CRH}$ and AVP mRNA levels in the hypothalamus under basal B conditions. Cortical lesions produced a similar, albeit less pronounced, effect. Moreover, Sapolsky et al. (1990) found that portal concentrations of CRH and AVP were negatively correlated with hippocampal glucocorticoid receptor occupancy. Interestingly, hippocampal glucocorticoid receptor occupancy was significantly correlated with resting (prestress) portal concentrations of both CRH and AVP. These findings suggest that an increased glucocorticoid receptor signal at the level of the hippocampus is associated with decreased levels of hypophysial CRH and AVP.

$\mathrm{H}$ and $\mathrm{NH}$ animals have been found to differ in glucocorticoid receptor density and this difference is observed only in the hippocampus and frontal cortex (reviewed in Meaney et al., 1991; see also earlier references). There are no differences in glucocorticoid receptor density between $\mathrm{H}$ and $\mathrm{NH}$ animals in hypothalamus, pituitary, amygdala, or septum (Meaney et al., $1985 b$ ) or in hippocampal mineralocorticoid (type I corticosteroid) receptors (Sarrieau et al., 1988; Meaney et al., 1989, 1992). The differences in hippocampal glucocorticoid receptor density are consistent with the decreased CRH and AVP content in the median eminence of the $\mathrm{H}$ rats (and analogous to the findings of Sapolsky et al., 1990). Note that we found substantial glucocorticoid receptor occupancy $(\sim 35-40 \%)$ in response to the B-replacement dose used in this study in both $\mathrm{H}$ and NH animals. Although the percentage of receptor occupancy was comparable between the two groups, the significantly increased glucocorticoid receptor density in the $\mathrm{H}$ rats suggests that the actual magnitude of the hippocampal glucocorticoid receptor signal was substantially higher in $\mathrm{H}$ animals.

On the basis of these data, it seems reasonable to propose that (1) $\mathrm{H}$ and $\mathrm{NH}$ animals differ in delayed negative feedback (Meaney et al., 1989), and that this difference is reflected in differential rates of CRH and AVP synthesis in the paraventricular nucleus of the hypothalamus; (2) that differences in negative-feedback regulation are apparent even in response to basal B signals; and (3) in response to stress therc is a grcater release of $\mathrm{CRH}$ and/or AVP in the $\mathrm{NH}$ animals, (4) giving rise to a greater increase in plasma ACTH levels and (5) a greater increase in plasma B levels, which persists for a longer period of time (i.e., higher poststress plasma B levels in the NH animals). Thus, differences between $\mathrm{H}$ and $\mathrm{NH}$ animals in HPA activity both during and following stress can occur independently of the stress-induced increase in plasma $B$.

In summary, postnatal handling during the early postnatal period leads to increased glucocorticoid receptor density in the hippocampus and is associated with enhanced negative-feedback control over HPA function. It is likely that this plasticity reflects a basic process, whereby the early environment is able to "fine tune" the sensitivity and efficiency of certain neuroen- 
docrine systems that mediate the animal's response to stimuli that threaten homeostasis. Such plasticity is likely to be of considerable importance to a species like the rat, which prospers in a tremendous range of ecological niches. The differences in negative-feedback sensitivity appear to be associated with differences in CRH and AVP release during stress, and thus determine, in part, individual differences in the sensitivity of the HPA axis to stress. Under the appropriate conditions, these differences in HPA function appear to predict vulnerability to neuropathology in later life (see Meaney et al., 1988a).

\section{References}

Ader R, Grota LJ (1969) Effects of early experience on adrenocortical reactivity. Physiol Behav 4:303-305.

Akana SF, Cascio CS, Du J-Z, Levin N, Dallman MF (1986) Reset of feedback in the adrenocortical system: an apparent shift in sensitivity of adrenocorticotropin to inhibition by corticosterone between morning and evening. Endocrinology 119:2325-2332.

Akana SF, Jacobson L, Cascio CS, Shinsako J, Dallman MF (1988) Constant corticosterone replacement normalizes basal adrenocorticotropin (ACTH) but permits sustained ACTH hypersecretion after stress in adrenalectomized rats. Endocrinology 122:1337-1342.

Akana SF, Scribner KA, Bradbury MJ, Strack AM, Walker C-D, Dallman MF (1992) Feedback sensitivity of the rat hypothalmo-pituitary-adrenal axis and its capacity to adjust to exogenous corticosterone. Endocrinology 131:585-594.

Antoni FA (1986) Hypothalamic control of ACTH secretion: advances since the discovery of 41-residue corticotropin-releasing factor. Endocrinol Rev 7:351-370.

Bradbury MJ, Cascio CS, Scribner KA, Dallman MF (1991) Stressinduced adrenocorticotropin secretion: diurnal responses and decreases during stress in the evening are not dependent on corticosterone. Endocrinology 129:99-108.

Bradford M (1976) A rapid and sensitive method for quantitation of microgram quantities of protein utilizing the principle of protein-dye binding. Anal Biochem 72:248-254.

Dallman MF, Akana S, Cascio CS, Darlington DN, Jacobson L, Levin N (1987) Regulation of ACTH secretion: variations on a theme of B. Rec Prog Horm Res 43:113-173.

Grota LJ (1975) Effects of early experience on the metabolism and production of corticosterone in rats. Dev Psychobiol 9:211-215.

Herman JP, Schafer MK-H, Young EA, Thompson R, Douglass J, Akil H, Watson SJ (1989) Evidence for hippocampal regulation of neuroendocrine neurons of the hypothalamo-pituitary-adrenocortical axis. J Neurosci 9:3072-3082.

Hess JL, Denenberg VH, Zarrow MX, Pfeifer WD (1969) Modification of the corticosterone response curve as a function of handling in infancy. Physiol Behav 4:109-112.

Jacobson L, Sapolsky RM (1991) The role of the hippocampus in feedback regulation of the hypothalamic-pituitary-adrenal axis. Endocrinol Rev 12:118-134.

Jacobson L, Akana SF, Cascio CS, Shinsako J, Dallman MF (1988) Circadian variations in plasma corticosterone permit normal termination of adrenocorticotropin responses to stress. Endocrinology 122: 1342-1348.

Krey LC, Lu K, Butler W, Hotchkiss J, Piva F, Knobil E (1975) Surgical disconnections of the medial basal hypothalamus and pituitary function in the rhesus monkey. II. GH and cortisol secretion. Endocrinology 96:1088-1096.

Levin N, Akana SF, Jacobson L, Kuhn RW, Siiteri PK, Dallman MF (1987) Plasma ACTH is more sensitive than transcortin production or thymus weight to inhibition by corticosterone in rats. Endocrinology 121:1104-1110.

Levine S (1957) Infantile experience and resistence to physiological stress. Science 126:405-406.

Levine S (1962) Plasma-free corticosteroid response to electric shock in rats stimulated in infancy. Science 135:795-796.

Levine S (1970) The pituitary-adrenal system and the developing brain. Prog Brain Res 32:79-102.

Levine S, Haltmeyer GC, Karas GG, Denenberg VH (1967) Physiological and behavioral effects of infantile stimulation. Physiol Behav $2: 55-63$.
Linton EA, Tilders FJH, Hodgkinson S, Berkenbosch F, Vermes I, Lowry PJ (1985) Stress-induced secretion of adrenocorticotropin in rats is inhibited by antisera to corticotropin-releasing factor and vasopressin. Endocrinology 116:966-970.

Martin CE, Cake MH, Hartmann PE, Cook IF (1975) Relationship between foetal corticosteroids, maternal progesterone, and parturition in the rat. Acta Endocrinol (Copenh) 84:167-176.

McEwen BS, De Kloet ER, Rostene WH (1986) Adrenal steroid receptors and actions in the nervous system. Physiol Rev 66:11211150 .

Meaney MJ, Aitken DH, Bodnoff SR, Iny LJ, Sapolsky RM (1985a) The effects of postnatal handling on the development of the glucocorticoid receptor systems and stress recovery in the rat. Prog Neuropsychopharmacol Biol Psychiatry 7:731-734.

Meaney MJ, Aitken DH, Bodnoff SR, Iny LJ, Tatarewicz JE, Sapolsky RM (1985b) Early, postnatal handling alters glucocorticoid receptor concentrations in selected brain regions. Behav Neurosci 99:760-765.

Meancy MJ, Aitken DH, Sapolsky RM (1987) Thyroid hormones influence the development of hippocampal glucocorticoid receptors in the rat: a mechanism for the effects of postnatal handling on the development of the adrenocortical stress response. Neuroendocrinology 45:278-283.

Meaney MJ, Aitken DH, Bhatnagar S, Van Berkel C, Sapolsky RM (1988a) Postnatal handling attenuates neuroendocrine, anatomical, and cognitive impairments related to the aged hippocampus. Science 238:766-768.

Meaney MJ, Viau V, Bhatnagar S, Aitken DH (1988b) Occupancy and translocation of hippocampal glucocorticoid receptors during and following stress. Brain Res 445:198-203.

Meaney MJ, Aitken DH, Sharma S, Viau V, Sarrieau A (1989) Postnatal handling increases hippocampal glucocorticoid receptors and enhances adrenocortical negative-feedback efficacy in the rat. Neuroendocrinology 50:597-604

Meaney MJ, Mitchell JB, Aitken DH, Bhatnagar S, Bodnoff SR, Iny LJ, Sarrieau A (1991) The effects of neonatal handling on the development of the adrenocortical response to stress: implications for neuropathology and cognitive deficits in later life. Psychoneuroendocrinology 16:85-103.

Meaney MJ, Aitken DH, Sharma S, Viau V (1992) Basal ACTH, corticosterone, and corticosterone-binding globulin levels over the diurnal cycle, and hippocampal type I and type II corticosteroid receptors in young and old, handled and nonhandled rats. Neuroendocrinology 55:204-213

Meyer JS, Micco DJ, Stephenson B, Krey LC, McEwen BS (1979) Subcutaneous implantation method for chronic glucocorticoid replacement therapy. Physiol Behav 22:867-870.

Mitchell JB, Iny LJ, Meaney MJ (1990) The role of serotonin in the development and environmental regulation of hippocampal type II corticosteroid receptors. Dev Brain Res 55:231-235.

Nakane T, Aughya T, Kanie N, Hollander CS (1985) Evidence for the role of endogenous corticotropin-releasing factor in cold, ether, immobilization, and a traumatic stress. Proc Natl Acad Sci USA 82: 1247-1251.

Plotsky PM (1987) Regulation of hypophysiotropic factors mediating ACTH secretion. Ann NY Acad Sci 512:205-217.

Plotsky PM, Bruhn TO, Vale WW (1985) Evidence for multifactor regulation of the adrenocortical secretory response to hemodynamic stimuli. Endocrinology 116:633-639.

Plotsky PM, Otto S, Sapolsky RM (1986) Inhibition of immunoreactive corticotropin-releasing factor into the hypophysial-portal circulation by delayed glucocorticoid feedback. Endocrinology 119:11261130.

Reul JMHS, De Kloet ER (1985) Two receptor systems for corticosterone in rat brain: microdistribution and differential occupation. Endocrinology 117:2505-2511.

Rivier C, Plotsky PM (1986) Mediation by corticotropin-releasing factor of adenohypophysial hormone secretion. Annu Rev Physiol 48:475-489.

Sapolsky RM, Krey LC, McEwen BS (1984) Glucocorticoid-sensitive hippocampal neurons are involved in terminating the adrenocortical stress response. Proc Natl Acad Sci USA 81:6174-6177.

Sapolsky RM, Krey LC, McEwen BS (1986) The neuroendocrinology of stress and aging: the glucocorticoid cascade hypothesis. Endocrinol Rev 7:284-301.

Sapolsky RM, Armanini MP, Packan DR, Sutton SW, Plotsky PM 
(1990) Glucocorticoid feedback inhibition of adrenocorticotropic hormone secretagogue release: relationship to corticosteroid receptor occupancy in various limbic sites. Neuroendocrinology 51:328-336.

Sarrieau A, Sharma S, Meaney MJ (1988) Postnatal development and environmental regulation of hippocampal glucocorticoid and mineralocorticoid receptors in the rat. Dev Brain Res 43:158-162.

Walker C-D, Akana SF, Cascio CS, Dallman MF (1990) Adrenalectomy in the neonate: adult-like adrenocortical system responses to both removal and replacement of corticosterone. Endocrinology 127: $832-842$.
Young EA, Akana S, Dallman MF (1990) Decreased sensitivity to glucocorticoid fast feedback in chronically stressed rats. Neuroendocrinology 51:536-542.

Zarrow MX, Campbell PS, Denenberg VH (1972) Handling in infancy: increased levels of the hypothalamic corticotropin releasing factor (CRF) following exposure to a novel situation. Proc Soc Exp Biol Med 356:141-143. 